\title{
RELASI ANTARA MUSLIM DENGAN NON MUSLIM
}

\author{
Andi Rahman \\ Institut Perguruan Tinggi Ilmu Alquran (PTIQ) Jakarta \\ Jl Batan1. N0 2 kel lebak bulus kecamatan cilandak Jakarta selatan \\ Email: andiwowo@yahoo.com
}

\begin{abstract}
The Relationship between Muslims and Non-Muslims. History of the relationship of the Prophet Muhammad and the Muslims with the Christians and Jews is real. Islam recognizes the plurality of the religion and does not coerce others in doing the dakwah. Islam does not come to kill and destroy other religions, but to make mutual relationship and live peacefully and cooperatively side by side. Especially in term of social interaction (mu'amalah) and daily interaction with the non-Muslims. Islam teaches flexibility and mutual respect.
\end{abstract}

Keywords: Tolerance, Religion, Islam

Abstrak: $\quad$ Relasi Antara Muslim Dengan Non Muslim. sejarah tentang hubungan Nabi
Muhammad dan umat Islam dengan kaum Nashrani dan Yahudi.Nyata bahwa
Islam mengakui pluralitas agama dan tidak melakukan pemaksaan dalam
berdakwah. Islam tidak datang untuk menghabisi dan memusnahkan agama
lain, melainkan agar para pemeluk agama saling hidup damai berdampingan
dan bekerja sama. Terlebih dalam masalah interaksi sosial (mu'amalah) dan
pergaulan sehari-hari dengan orang kafir, Islam mengajarkan keluwesan dan
sikap saling menghargai

Kata kunci: toleransi, agama, Islam

\section{Pendahuluan}

"Jangan melakukannya di lobang tanah, yang kemungkinan terdapat hewan hidup di dalamnya." Demikian salah satu etika buang air besar dan kecil, seperti yang diterangkan oleh al-Imam Abu Syuja' dalam karyanya yang monumental, Ghayah al-Taqrib.

Kitab yang merupakan 'konsumsi wajib' para santri di hampir seluruh pesantren di pulau Jawa, memiliki banyak kitab syarh atau kitab yang menjadi penjelasnya dan yang mengomentarinya, seperti al-Iqna', al-Tadzhib, dan Fath al-Qarib.Bahkan Fath al-Qarib sendiri memiliki kitab syarhnya sendiri, seperti Hasyiyah al-Bajuri, Kifayah al-Akhyar, dan Tausyikh. 
Syaikh Nawawi al-Bantani, seorang ulama Indonesia yang mendapat julukan sayyid ulama' al-hijaz (mahaguru ulama tanah Hijaz), mengomentari ungkapan di atas, "Bisa jadi di dalam lobang itu terdapat hewan yang lemah, akibatnya hewan tadi menjadi terganggu dan tersakiti.Mungkin juga di dalamnya terdapat hewan yang kuat, maka kita yang justru akan terganggu dan tersakiti. Atau bahkan lobang tersebut merupakan tempat tinggal Jin... ${ }^{1}$

Dalam Surat al-Anbiya ayat 107 dinyatakan, "Dan tiadalah Kami mengutus kamu, melainkan untuk (menjadi) rahmat bagi semesta alam". Dengan lugas dinyatakan bahwa Islam merupakan agama yang membawa rahmat dan kesejahteraan bagi semua seluruh alam semesta, termasuk hewan, tumbuhan dan jin. Kezaliman terhadap binatang, akan dipertanggungjawabkan di Akhirat. Dalam sebuah hadis dinyatakan, Siapa yang membunuh burung kecil, tanpa alasan yang dibenarkan ('abast), maka burung itu akan melayangkan 'somasi' di hadapan Allah berupa tuntutan: Ya Tuhanku, orang itu telah membunubku tanpa alasan, ia membunuhku tanpa kemanfaatan. ${ }^{2}$

Senada dengan Hadis di atas, Shahabat Abdullah bin 'Amr berkata bahwasanya Rasulullah pernah bersabda, "Siapa yang membunuh burung, atau hewan lain yang lebih kecil darinya tanpa hak, maka Allah akan meminta pertanggungjawaban kepadanya. "Rasulullah saat ditanya tentang hak burung tersebut, beliau bersabda, "Burung tersebut memiliki hak untuk disembelih untuk kemudian dimakan, bukan dipotong lehernya untuk kemudian dilempar (tersia-sia)."3

Sungguh, hak hewan dihormati oleh Islam. Apapun bentuk kesewenang-wenangan dan kezaliman terhadap hewan, akan mendapat kecaman dari Agama. Dalam sebuah hadis diriwayatkan, "Sesungguhnya Rasulullah bersabda: Seorang wanita disiksa sebab seekor kucing yang dikurungnya. Ia tidak memberinya makan, hingga akhirnya kucing itu mati

${ }^{1}$ Al-Bantani (Muhammad bin Umar), Tausyikh 'ala Ibn Qasim, (Surabaya: TB. Al-Hidayah, tt), hal. 21

${ }^{2}$ Al-Imam Ibn Hibban, Shahih Ibn Hibban (Beirut: Muassasah al-Risalah, 1993), cet. III, jilid XIII, hal. 214, dan al-Imam al-Thabrani, al-Mu'jam al-Kabir (Musol: Maktabah al-'Ulum wa al-Hikam, 1983), cet. II, jilid VII hal. 317.

${ }^{3}$ Al-Imam al-Hakim,al-Mustadrak 'Ala al-Shahihain (Beirut: Dar al-Kutub al-'Ilmiyah, 1990), cet. I, jilid IV, hal.261; Al-Imam al-Baihaqi,al-Sunan al-Kubra, (Mekkah al-Mukarramah, Maktabah Dar al-Baz, 1994), jilid IX, hal. 86; Al-Imam al-Darimi,Sunan al-Darimy, (Beirut: Dar al-Kitab al'Araby, 1407 H), I jilid II, hal. 115. 
karena kelaparan. Ia juga tidak melepaskannya, hingga kucing tadi bisa mencari makan dengan sendirinya". Rasulullah menambahkan, "Wanita tadi dihukum masuk Neraka". ${ }^{4}$

Masih dalam konteks menghormati hak hewan, Nabi Muhammad menyuruh kita untuk menajamkan pisau yang digunakan dalam penyembelihan. Hal ini dimaksudkan agar hewan yang disembelih tidak terlalu lama merasakan sakitnya penyembelihan. Sabda beliau, "Ketika kalian menyembelih (hewan ternak), maka perbaguslah penyembelihanmu. Hendaknya pisau penyembelihan ditajamkan, dan hewan sembelihan dibuat merasa 'nyaman'.5

Al-Imam Yahya bin Syaraf al-Nawawi mengomentari kata 'nyaman' pada hadis di atas, "Hendaknya menajamkan pisau penyembelihan dan mempercepat proses penyembelihan.Dianjurkan untuk tidak menajamkan pisau di hadapan hewan yang akan disembelih, dan tidak melakukan penyembelihan seekor hewan di hadapan hewan lain yang juga akan disembelih. Demikian seterusnya."

Demikian sebagian penghormatan yang diberikan Islam terhadap semut, burung, kucing, dan hewan-hewan lainnya.Sesungguhnya masih banyak lagi hak-hak hewan yang dijaga dan dipelihara oleh Islam.Sikap menghormati ini juga berlaku pada semua makhluk Allah Ta'ala, termasuk tetumbuhan dan jin. ${ }^{6}$

Dibandingkan dengan perlakuan terhadap hewan dan tetumbuhan, Islam lebih menghormati dan menghargai manusia. Penghormatan ini dengan jelas dinyatakan Allah Ta'ala dalam al-Quran surah al-Isra ayat 70, "Dan sesungguhnya telah Kami muliakan anak-anak Adam...". Yang patut digaris bawahi dari ayat ini, adalah bahwa penghormatan ini tidak

\footnotetext{
${ }^{4}$ Al-Imam al-Bukhari, Shahih al-Bukhari(Beirut: Dar Ibn Katsir, 1987), cet. III, jilid II, hal. 834 dan jilid III, hal.1205; Al-Imam Ibn Hibban, Shahih Ibn Hibban, jilid II, hal.305; Al-Imam alBaihaqi, al-Suna al-Kubra, jilid V, hal. 214;Al-Imam Muslim al-Naisabury, Shahih Muslim, (Beirut: Dar Ihya al-Turats al-'Araby, tt), jilid IV, hal. 2110; Al-Imam al-Thabrani dalam al-Mu'jam alAusath, (Cairo: Dar al-Haramain, 1415 H.), jilid VII, hal. 273.

${ }^{5}$ Al-imam Muslim, Shahih Muslim, jilid III, hal. 1548; Al-Imam Abu Dawud, Sunan Abu Dawud, (Beirut: Dar al-Fikr, tt), jilid III, hal. 100; Al-Imam Ibn Hibban, Shahih Ibn Hibban, jilid XIII, hal. 199; Al-Imam al-Tirmidzi, Sunan al-Tirmidzi, (Beirut: Dar Ihya al-Turats al-'Araby, tt), jilid IV, hal 23; Al-Imam Ibn Majah, Sunan Ibn Majah, (Beirut: Dar al-Fikr, tt), jilid II, hal. 1058; kesemuanya dari Shahabat Syaddad bin Aus.

${ }^{6}$ Mari renungi firman Allah Ta'ala dalam surah al-A'raf ayat 56," Dan janganlah kamu membuat kerusakan di muka bumi, sesudah (Allah) memperbaikinya...".
} 
terbatas kepada orang-orang Islam, melainkan juga kepada mereka yang tidak beragama Islam, atau yang seterusnya akan kita sebut sebagai non muslim. Karena baik mereka yang beragama Islam maupun mereka yang non muslim, kesemuanya merupakan "anak-anak Adam".

Namun karena tipologi orang-orang Islam dan non muslim tidak sama, bahkan tipologi non muslim pun berbeda-beda.Maka perlakuan dan penghor-matan Islam kepada mereka juga berbeda.

\section{Tipologi Non Muslim}

Non muslim, atau orang yang tidak menganut agama Islam terbagi menjadi dua golongan:

Pertama, golongan Pagan (al-Musyrikun), yaitu orang yang tidak menganut agama semitik (Samawi).Mereka adalah pemeluk agama Budha, Hindu, Konghucu, Majusi, Zarathusta (Zoroaster), penganut aliran kepercayaan dan bijak bestari, dan lain sebagainya.Kedua, golongan $\mathrm{Abl}$ al-Kitab, atau mereka yang menganut agama semitik, yaitu Yahudi dan Nashrani.

Tipologi non muslim ke dalam golongan pagan dan ahli kitab ini, berdasarkan firman Allah Ta'ala dalam surah al-Bayyinah ayat 1, "Orangorang kafir yakni ahli kitab dan orang-orang musyrik (mengatakan bahwa mereka) tidak akan meninggalkan (agamanya) sebelum datang kepada mereka bukti yang nyata." Pada surah yang sama ayat 6 dinyatakan, "Sesungguhnya orang-orang kafir yakni abli Kitab dan orang-orang musyrik (akan masuk) ke neraka Jahannam; mereka kekal di dalamnya. Mereka itu adalah seburukburuk makhluk."

Kedua golongan ini dalam literatur Islam terbagi menjadi tiga, yaitu: Harby, dzimmy (mu'ahad), dan musta'man.

Harby adalah orang kafir (non muslim) yang memerangi umat Islam. Dzimmy adalah non muslim yang telah mendapat jaminan keselamatan dan keamanan dari pemerintah dan umat Islam. Mereka mendapatkan keamanan dengan membayar upeti (jizyah) kepada pemerintah.Sementara musta'man adalah orang kafir yang didatangkan oleh negara yang berpenduduk muslim untuk keperluan tertentu, seperti perwakilan diplomasi dan duta besar. ${ }^{7}$

\footnotetext{
${ }^{7}$ Ali Mustafa Yaqub, Kerukunan Umat dalam Perspektif Al-Quran dan Hadis, (Jakarta: Pustaka Firdaus, 2000), hal. 73-74
} 
Semua non muslim kecuali kafir harby, tidak boleh diperangi, didzalimi, dan diganggu. Adapun kafir harby, maka kita wajib memerangi mereka selama mereka memerangi umat Islam, hingga mereka menyatakan tunduk kepada umat Islam.

\section{Interaksi Nabi Muhammad dengan Non Muslim}

Nabi Muhammad adalah penafsir Al-Quran yang utama. Maksud dari Al-Quran terkait relasi muslim dengan non muslim, bisa dilihat dari bagaimana sikap beliau terhadap non muslim.

Orang Nashrani yang pertama kali dikenal Nabi adalah pendeta Waraqah bin Naufal, disebutkan bahwa ia adalah sepupu (Ibn 'amm) Umm al-Mukminin Khadijah. Tidak banyak literatur yang mengisahkan kehidupan pendeta ini, atau hubungannya dengan Nabi.Sedikit yang kita ketahui tentangnya, yaitu ketika Rasulullah diajak oleh Khadijah mengunjunginya untuk memberitahukan kedatangan Malaikat Jibril dengan membawa wahyu ayat "Iqra".

Waraqah berkata, "Alangkah beruntungnya, seandainya aku masih hidup dan masih kuat ketika engkau diusir oleh kaummu. "Mendengar perkataannya, Nabi terkejut dan balik bertanya, "Apakah aku akan diusir oleh kaumku sendiri?". Waraqah menjawab, "Ya, karena tidak ada seorang pun yang mendapat tugas sepertimu, kecuali akan dimusubi oleh kaumnya. Dan sekira aku masih hidup saat itu, aku pasti akan membelamu semampuku". ${ }^{\mathrm{T} T \mathrm{k}}$ lama waktu berselang, Waraqah meninggal dunia.

Meskipun tidak banyak keterangan yang sampai kepada kita tentang dirinya, kita mengetahui bahwa pendeta Nashrani ini, telah menunjukkan rasa simpati kepada Nabi Muhammad.

Delapan tahun sebelum peristiwa Hijrah ketika teror dan intimidasi yang dilakukan kaum musyrikin kepada umat Islam memuncak, Rasulullah memerintahkan kaum muslimin untuk berhijrah (mengungsi) ke Abessenia (Habasyah). Kaum muslimin sebanyak 16 orang kemudian barangkat ke Abessenia dan tinggal di sana selama bulan Sya'ban dan Ramadhan. Pada bulan ketiga, yaitu bulan Syawal, mereka mendapatkan kabar bahwa situasi Mekkah sudah aman dan kondusif. Mereka lalu

${ }^{8}$ Al-Imam al-Bukhari, Shahih al-Bukhari, jilid I, hal. 4; Al-Imam Muslim al-Naisabury, Shahih Muslim., jilid I, hal 141. 
kembali ke Mekkah. Namun ternyata kabar iu tidak benar, Mekkah masih belum aman, sehingga mereka kembali mengungsi untuk kedua kalinya ke Abessenia, dan kali ini jumlah mereka bertambah menjadi 102 orang. Rombongan kedua ini lama tinggal di Abessenia, yaitu selama 14 tahun, mulai tahun $7 \mathrm{SH}$ (Sebelum Hijrah) hingga $7 \mathrm{H}$.

Oleh al-Najasyi (raja Abessenia), kaum muslimin diperlakukan dengan baik, padahal saat itu ia dan penduduk negeri Abessenia beragama Nashrani. Bahkan ketika kaum muslimin hendak menyusul Nabi ke Madinah pada tahun $7 \mathrm{H}$, al-Najasyi menyediakan dua kapal laut untuk mengangkut mereka. ${ }^{10}$

Ketika Rasulullah sudah menetap di Madinah, beliau pernah didatangi oleh rombongan orang-orang Nashrani dari wilayah Najran yang berjumlah enam puluh orang yang dipimpin oleh Uskup Abu al-Haritsah bin 'Alqamah. Najran adalah sebuah negeri yang terletak di kawasan sebelah selatan jazirah Arab.Dengan memakai jubah katun bercorak lorek buatan Yamandan selendang bersulam sutera, mereka menghadap Rasulullah. Saat itu beliau dan para shahabat sedang melaksanakan shalat Ashar berjamaah.Mereka pun bermaksud melaksanakan ibadah (kebaktian) di masjid nabi dengan menghadap ke arah timur. Melihat kejadian ini, para shahabat bermaksud melarangnya, namun Rasulullah membiarkan mereka melakukan kebaktian. ${ }^{11}$

Peserta rombongan kemudian berdiskusi dengan Rasulullah seputar masalah-masalah keimanan, kemudian pulang ke Najran. Tidak ada satu pun yang menyatakan masuk Islam, dan Rasulullah juga tidak memaksa mereka untuk masuk Islam, namun beberapa waktu kemudian, dua orang tokoh mereka, yaitu al-Sayid dan al-Aqib, datang kembali ke Madinah dan menyatakan keislaman mereka. ${ }^{12}$

Demikian sedikit kisah tentang hubungan dan interaksi Nabi dengan kaum Nashrani.

Di kota Madinah dan daerah-daerah sekitarnya, banyak terdapat masyarakat Yahudi, khususnya di kota Khaibar. Hubungan Rasulullah bersama shahabat dengan mereka juga menarik untuk disimak, misalnya pada tahun

${ }^{9}$ Ali Mustafa Yaqub, Kerukunan Umat dalam Perspektif Al-Quran dan Hadis, hal. 34-35

10 Ali Mustafa Yaqub, Kerukunan Umat dalam Perspektif Al-Quran dan Hadis, hal.35

11 Ali Mustafa Yaqub, Kerukunan Umat dalam Perspektif Al-Quran dan Hadis, hal.35

12 Ali Mustafa Yaqub, Kerukunan Umat dalam Perspektif Al-Quran dan Hadis, hal.35 
7 H. Rasulullah menikahi Shofiyah puteri Huyai bin Akhtab, seorang tokoh Yahudi dari bani Quraidzah di Khaibar. Meskipun Shofiyah masuk Islam dan mendapat julukan Umm al-Mukminin, namun mertua Rasulullah yang bernama Huyai bin Akhtab, tetap menganut agama Yahudi hingga meninggal dunia. $^{13}$

Dalam beberapa hadis kita dapati keterangan bahwa Umm alMukminin Aisyah sering 'ngobrol-ngobrol' dan berdiskusi dengan wanita Yahudi di rumah Nabi. Dalam sebuah hadis dikisahkan bahwa, "Seorang wanita yahudi mendatangi Aisyah dan berkata: Semoga Allah menjagamu dari siksa kubur. Kemudian Aisyah bertanya kepada Nabi tentang adanya siksa kubur." ${ }^{\prime 4}$

Memang ada gesekan-gesekan antara kaum muslimin dengan kaum Yahudi, bahkan Nabi pernah mengusir Bani al-Nadhir, namun hal tersebut bukan disebabkan keyahudian mereka, melainkan karena pengkhianatan dan pembatalan secara sepihak oleh mereka terhadap perjanjian yang telah disepakati.

Bahkan menjelang wafat, Nabi Muhammad masih berhubungan dengan orang yahudi. Beliau meminjam gandum sebanyak 30 sho' dari seorang Yahudi yang bernama Abu Syahm, dengan menjaminkan baju perang beliau.Umm al-Mukminin Aisyah berkata, "Rasulullah wafat dan baju perang beliau digadaikan kepada seorang Yahudi untuk gandum sebanyak 30 sho'. "'5 Hutang beliau ini kemudian dilunasi oleh Shahabat Ali bin Abu Thalib..

Adapun sikap kita akan keyakinan dan keimanan mereka harus tegas; bahwa akidah mereka adalah batil dan sesat. Apabila mereka mati dalam keadaan kufur, maka mereka akan kekal di dalam Neraka. Shahabat Abu Hurairah berkata, "Bahwa Rasulullah pernah bersabda: Demi Allah Dzat Yang Menguasai jiwa Muhammad, tidak ada seorang Yahudi dan Nashrani pun yang mendengar tentang diriku, kemudian ia mati tanpa mengimani ajaran yang aku bawa, kecuali ia akan menjadi penghuni Neraka" ${ }^{16}$

\footnotetext{
${ }^{13}$ Ali Mustafa Yaqub, Kerukunan Umat dalam Perspektif Al-Quran dan Hadis, hal.38.

${ }^{14}$ Al-Imam al-Bukhari,Shahih al-Bukhari, jilid I, hal. 359; Al-Imam Muslim, Shabih Muslim., jilid I, hal. 410

${ }^{15}$ Al-Imam al-Bukhari, Shahih al-Bukhari, jilid II, hal. 887;Al-Imam al-Syafi'i,Musnad alSyafi'I, (Beirut: Dar al-Kutub al-'Ilmiyah, tt), jilid I, hal. 139.

${ }^{16}$ Al-Imam Muslim, Shahih Muslim, jilid I, hal. 134; Al-Imam Ahmad, Musnad, (Mesir: Muassasah Qurthubah, tt), jilid II, hal. 317
} 
Dalam hal ini, hendaknya sikap kita selaras dengan ayat 6 surah alKafirun, "Untukmulah agamamu, dan untukkulah, agamaku".

\section{Berperang atas Nama Agama}

Dengan menyitir ayat-ayat tentang jihad dan perintah memerangi orang kafir, beberapa orang ekstrim dan sempit dalam memahami nilai-nilai kemanusiaan yang diemban Islam, menyerukan perang dan konfrontasi dengan semua orang kafir, tanpa terkecuali, walaupun mereka tidak menyerang dan mengganggu umat Islam.

Para ekstrimis ini, mengutip pendapat al-Imam Ibn al-'Arabi, seperti yang terdapat dalam kitab al-Itqan karangan al-Imam al-Suyuthi ${ }^{17}$, bahwa semua ayat al-Quran yang berbicara tentang pemaafan terhadap orang kafir dan sikap toleransi kita terhadap mereka, yang berjumlah seratus dua puluh empat ayat ${ }^{18}$, kesemuanya dieliminasi (mansukhakh) oleh "ayat pedang", yaitu ayat kelima dari surat al-Taubah, Apabila sudah habis bulan-bulan haram itu, maka bunublah orang-orang musyrikin itu di mana saja kamu jumpai mereka, dan tangkaplah mereka. Kepunglah mereka dan intailah di tempat pengintaian.Jika mereka bertaubat dan mendirikan shalat dan menunaikan zakat, maka berilah kebebasan kepada mereka untuk berjalan. Sesungguhnya Allah Maha Pengampun lagi Maha Penyayang."

Para ekstrimis juga berdalih dengan Hadis Nabi, "Aku diperintahkan untuk memerangi seluruh manusia hingga mereka bersaksi bahwa tidak ada tuhan kecuali Allah, dan bersaksi bahwa Muhammad adalah utusan Allah, juga agar mereka mendirikan shalat dan menunaikan zakat... "19

Mereka berpendapat bahwa memerangi orang kafir adalah wajib hukumnya, baik mereka mendzalimi dan menyerang kaum muslimin, ataupun tidak.

Ada beberapa alasan mengapa klaim nasikh ini ditolak, salah satunya

${ }^{17}$ Al-Suyuthi, al-Itqan $f i$ 'Ulum al-Quran, ttp., tth., juz II hal. 24

${ }^{18}$ Menurut perhitungan al-Imam Muhammad al-Andalusi dalam kitabnya, kitab al-Tashil li 'Ulum al-Tanzil, jumlah ayat-ayat tersebut tidak sampai seratus dua puluh empat, melainkan hanya seratus empat belas ayat.Setelah penulis mengadakan penghitungan kembali ayat-ayat tersebut menurut perincian yang disebutkan sendiri oleh Imam Muhammad al-Andalusy dalam kitabnya tersebut, jumlah ayatnya hanya sampai seratus enam ayat yang terdapat dalam lima puluh satu surat.

${ }^{19}$ Al-Imam al-Bukhari, Shahih al-Bukhari, jilid I, hal. 17; Al-Imam Muslim, Shahih Muslim, jilid I, hal.52, dari Shahabat Abu Hurairahdan Ibn Umar. 
adalah ketidaklogisan satu ayat vis a vis seratus dua puluh empat ayat, di mana ayat tunggal tersebut 'mengalahkan' ayat yang jumlahnya lebih dari seratus kali lipat banyaknya. Terlebih lagi bila klaim eliminasi ini dibenarkan, maka setidaknya ada 42,4\% ayat ahkam (ayat yang memiliki kandungan hukum perundang-undangan) menjadi mulghah dan tidak memiliki konsekuensi hukum formal ${ }^{20}$. Atau akan ada 3,5\% ayat yang mulghah dari jumlah total ayat dalam al-Quran ${ }^{21}$.

Kemudian harus dipahami bahwa perintah memerangi orang kafir, berlaku ketika mereka memerangi kita, seperti penegasan yang terdapat dalam al-Quran surah al-Baqarah ayat 190, "Dan perangilah di jalan Allah orang-orang yang memerangi kamu, (tetapi) janganlah kamu melampaui batas, karena sesungguhnya Allah tidak menyukai orang-orang yang melampaui batas".

Pada ayat-ayat selanjutnya dinyatakan, "Dan bunublah mereka di mana saja kamu jumpai mereka, dan usirlah mereka dari tempat mereka telah mengusir kamu (Mekah); dan fitnah itu lebih besar bahayanya dari pembunuhan, dan janganlah kamu memerangi mereka di Masjidil Haram, kecuali jika mereka memerangi kamu di tempat itu. Jika mereka memerangi kamu (di tempat itu), maka bunublah mereka.Demikianlah balasan bagi orang-orang kafir.Kemudian jika mereka berhenti (dari memusuhi kamu), maka sesungguhnya Allah Maha Pengampun lagi Maha Penyayang.Perangilah mereka itu, sehingga tidak ada fitnah lagi dan (sehingga) ketaatan itu hanya semata-mata untuk Allah. Jika mereka berhenti (dari memusuhi kamu), maka tidak ada permusuhan (lagi), kecuali terhadap orang-orang yang zalim."

Rasulullah sebagai orang yang paling memahami al-Quran, tidak membunuh Yahudi yang hidup dan tinggal di kota Madinah dan kotakota sekitarnya, melainkan beliau bergaul dan berinteraksi dengan baik. Demikian juga dengan orang-orang Nashrani dari Najran.Bahkan terhadap

${ }^{20}$ Dengan estimasi penghitungan 212 ayat : 500 ayat x $100 \%=42,4 \%$. Karena menurut para ulama jumlah ayat ahkam jumlahnya sekitar lima ratus buah

${ }^{21}$ Dengan estimasi penghitungan 212 ayat : 6200 ayat x $100 \%=3,4193 \%$. Al-Imam alDani berkata (seperti yang disebutkan dalam al-Itqan I/67), "Ulama sepakat bahwa jumlah ayat alQuran tidak kurang dari 6000 (enam ribu) ayat. Sebagian mereka ada yang mengatakan bahwa jumlah definitif ayat al-Quran tepat 6000 (enam ribu); Ada juga yang berkata bahwa jumlah definitifnya 6204 (enam ribu dua ratus empat); Ada yang berkata 6214 (enam ribu dua ratus empat belas); Ada juga yang berkata 6219 (enam ribu dua ratus sembilan belas); Ada juga yang berkata 6225 (enam ribu dua ratus dua puluh lima); Dan ada juga yang berkata 6236 (enam ribu dua ratus tiga puluh enam). 
kaum Majusi yang hidup di daerah Hajar, beliau tidak memerangi mereka, tetapi hanya memungut upeti dari mereka sebagaimana hal yang sama diberlakukan kepada kafir ahli kitab. ${ }^{22}$

Adapun pemahaman hadis yang diriwayatkan oleh Shahabat Ibn Umar bahwa Rasulullah diperintahkan untuk memerangi semua orang hingga mereka masuk Islam, maka harus dipahami secara kontekstual. Beliau tidak semerta-merta memerangi orang kafir tanpa alasan, adalah bukti bahwa hadis tersebut harus dimaknai sebagai perintah perang terhadap mereka yang enggan menyatakan keislaman dan tidak membayar upeti, serta merongrong kedamaian kaum muslimin.Atau bahwa ayat dan hadis tersebut, berkaitan dengan situasi perang, bukan dalam keadaan damai.

Masih dalam rangka memaknai hadis "pedang" riwayat Ibn Umar, Khalifah Abu Bakar memerangi orang-orang Islam yang membangkang dan enggan membayar zakat, padahal mereka sudah mengucapkan La ilaaha illa Allah. $^{23}$

Sikap dan perilaku kita terhadap non muslim, harus proporsional. Artinya kita akan memerangi mereka tanpa jerih dan takut, ketika mereka memerangi kita. Ketika mereka berlaku baik, maka kitapun dituntut untuk berbuat baik.

Allah Ta'ala berfirman dalam surah al-Mumtahanah ayat 8-9, "Allah tiada melarang kamu untuk berbuat baik dan berlaku adil terhadap orangorang yang tiada memerangimu karena agama dan tidak (pula) mengusir kamu dari negerimu. Sesungguhnya Allah menyukai orang-orang yang berlaku adil. Sesungguhnya Allah hanya melarang kamu menjadikan sebagai kawanmu orang-orang yang memerangi kamu karena agama dan mengusir kamu dari negerimu dan membantu (orang lain) untuk mengusirmu. Barangsiapa menjadikan mereka sebagai kawan, maka mereka itulah orang-orang yang zalim."

Dalam sebuah Hadis, Rasulullah bersabda, "Siapa yang membunuh orang kafir mu'ahad (yaitu kafir dzimmi yang telah mendapatkan perlindungan dari pemerintah), maka ia tidak dapat membau aroma surga.Aroma surga itu

${ }^{22}$ Al-Imam al-Bukhari, Shahih al-Bukhari, jilid III, hal. 1151.

${ }^{23}$ Padahal menurut Hadis Ibn Umar tersebut, mereka yang telah mengucapkan la ilaaha illallaah tidak boleh dibunuh. Ternyata setelah mengalami perdebatan antara khalifah dan beberapa shahabat seperti Umar bin al-Khathab, perang terhadap 'pembangkang zakat' tersebut terjadi juga, dengan landasan dekrit dari khalifah yang kemudian didukung oleh seluruh shahabat. 
dapat dibirup dari jarak perjalanan selama empat puluh tahun". ${ }^{24}$

Keterangan-keterangan di atas, menjelaskan kepada kita tentang kebolehan umat Islam berinteraksi dan ber-mu'amalah dengan non muslim, selama mereka bersikap koperatif dan tidak mengganggu kaum muslimin.

\section{Pustaka Acuan}

\section{Mushaf al-Quran al-Karim}

Al-Andalusi, Muhammad bin Ahmad.Kitab al-Tashil li 'Ulum al-Tanzil. Beirut: Dar al-Fikr.

Al-Baihaqi, Ahmad bin al-Husain.Al-Sunan al-Kubra.Mekkah alMukarramah: Maktabah Dar al-Baz. 1994.

Al-Bantani, Muhammad bin Umar.Tausyikh 'ala Ibn Qasim.Surabaya: TB. Al-Hidayah.

Al-Bukhari, Muhammad bin Ismail.Shahih al-Bukhari.Beirut: Dar Ibn Katsir. 1987.

Al-Busti, Muhammad bin Hibban.Shahih Ibn Hibban. Beirut: Muassasah al-Risalah. 1993.

Al-Darimi, Abdullah bin Abdurrahman.Sunan al-Darimy.Beirut: Dar alKitab al-'Araby. 1407 H.

Al-Naisaburi, Muhammad bin Abdillah al-Hakim.Al-Mustadrak 'Ala alShahihain. Beirut: Dar al-Kutub al-'Ilmiyah. 1990.

Al-Naisaburi, Muslim bin al-Hajjaj.Shahih Muslim. Beirut: Dar Ihya alTurats al-'Araby.

Al-Qazwini, Muhammad bin Yazid.Sunan Ibn Majah. Beirut: Dar al-Fikr.

Al-Sijistani, Sulaiman bin al-Asy'ats), Sunan Abu Dawud, (Beirut: Dar alFikr, tt).

Al-Suyuthi, Jalaluddin.Al-Itqan fi 'Ulum al-Quran. Beirut: Dar al-Fikr. 1951.

Al-Syaibani, Ahmad bin Muhammad bin Hanbal.Musnad Ahmad. Mesir: Muassasah Qurthubah.

Al-Syafi'i, Muhammad bin Idris.Musnad al-Syafi'i. (Beirut: Dar al-Kutub al'Ilmiyah.

${ }^{24}$ Al-Imam al-Bukhari, Shahih al-Bukhari, jilid III, hal. 1155; Al-Imam Ibn Majah, Sunan Ibn Majah, jilid II, hal.896; Al-Imam Ibn Hibban, Shahih Ibn Hibban, jilid XVI, hal. 392. 
Al-Thabrani, Sulaiman bin Ahmad.Al-Mu'jam al-Kabir. Musol: Maktabah al-'Ulum wa al-Hikam. 1983. Al-Mu'jam al-Ausath.Cairo: Dar al-Haramain $1415 \mathrm{H}$.

Al-Tirmidzi, Muhammad bin Isa.Sunan al-Tirmidzi.Beirut: Dar Ihya alTurats al-'Araby.

Yaqub, Ali Mustafa.Kerukunan Umat dalam Perspektif Al-Quran \& Hadis. Jakarta: Pustaka Firdaus. 2000. 